\title{
Socio-economic Aspects Influencing Rural Household Adoption of Improved Clean Cook Stoves Case Study: Rwanda
}

\author{
Niyonshuti Emmanuel*, Mushinzimana Isaac \\ African Centre of Excellence in Energy for Sustainable Development, Department of Energy Economics, University of Rwanda, Kigali, \\ Rwanda
}

\author{
Email address: \\ niyency@yahoo.fr (N. Emmanuel), mushinzisaac@gmail.com (M. Isaac) \\ ${ }^{*}$ Corresponding author
}

\section{To cite this article:}

Niyonshuti Emmanuel, Mushinzimana Isaac. Socio-economic Aspects Influencing Rural Household Adoption of Improved Clean Cook Stoves Case Study: Rwanda. American Journal of Modern Energy. Vol. 7, No. 4, 2021, pp. 45-50. doi: 10.11648/j.ajme.20210704.11

Received: March 18, 2021; Accepted: March 30, 2021; Published: August 23, 2021

\begin{abstract}
The major causes of deforestation worldwide from human activities is the reliance of world population on the biomass fuel for domestic energy consumption through cooking, water boiling, heating and lighting, the usage of biomass in inefficient way increase the fuel demand for the household. Despite of multiple social economic, health and environmental benefit of improved cook stove program, the program failed to capture the recognition worldwide and a set of sociocultural, economic, institutional barriers and cook stove and fuel characteristics contribute to the slow adoption of this program. This paper provides an evidence of household driving factors that play a crucial role in the uptake of improved cook stove empirically in Rwanda. The study was based on fifth integrated household living standards survey (EICV-5) carried by National Institute of Statistics of Rwanda. Using binary logistic regression analysis, the study shows that homeownership, age of household head, household location and household size are the main significant household factors influencing the adoption of improved cook stove while value of cook stove, amount spent on cooking fuel and time spend on cooking fuels are the most significant stove and fuel factors determining the adoption of usage of improved cook stove. The study revealed that for substantially improved rate of adoption they should be consistent and focused cooperation of government and non -governmental organizations to work in parallel for developing energy policy frameworks like dissemination of improved cook stoves.
\end{abstract}

Keywords: Biomass, Rural Household Improved Cook Stoves, Binary Logit Regression

\section{Introduction}

Worldwide, energy is very crucial in meeting households' basic need majorly for cooking, water boiling, heating and lighting. Worldwide over 3 billion people rely on solid fuels including biomass materials as the main source of energy for the household and more than $90 \%$ of the consumption took place in developing countries [21]. About of half of global population is dependent on traditional fuels and stoves to fulfill their energy prerequisite [21].

The study Designate that the traditional fuels and stove to be inefficiency and are presumed to contribute about a third of worldwide carbon monoxide emission and other pollutants in biomass smoke affecting global climate change [19]. Consequently, household's solid fuel low combustion affects both local and region quality of air to a long extend and hence influence human health [1] and [10] revealed that Globally exposure to smoke from household solid combustion is one the largest risk factor resulting in proximately 3.5 million premature death 4.5 global DALYs (Disability Adjusted Life years) in 2010. The pollutants emissions resulted from the process of fuels combustion are influenced by factors including fuels properties and stove design. [20] Illustrated that if no action takes place by 2030 approximately 0.9 million of population will die from infection associated with solid fuels cooking.

The Accessibility to modern clean cooking fuel is global challenge and hence fourth enough effort to design, adopt and use improved cook stove are the best intervention solution for enhancing the way biomass is used in addressing 
advice resulting impact [5].

In middle-income countries like Rwanda, intervention for improved cooking stove by the government donors and nongovernmental organization, it had promising impact on health and environment [18].

The study reported that improved cook stove has been the evident efficient tool that would benefit human health, environment and climate through decline in fuel wood harvesting and emissions [9]. Few effort have been devoted to understanding how improved cook stove are currently adopted for a long time sustainable use and this will ensure the social economic aspects that are well incorporated to ensure a long term sustained usage of improved cook stove.

They are some studies conducted on the socio economic factors influencing household adoption of improved cook stove which was developed for reducing the health and livelihood consequence resulting from the usage of solid cooking fuels, the study carried out by [2] the study carried out said that the transition from traditional to clean cooking fuel began in 1990s and the switching movement was slow especially in most of low income countries and many people still relying on traditional fuels for their cooking purpose and hence effort needed towards improvement the household usage of improved cook stoves.

the study identified various socio economic factors such as education, household size, income and price of cook stove, time spent in firewood collection as having influence on household adaptation of improved cook stove [11]. In Burkina Faso, the authors Observed that there is positive correlation between household income and fuels consumption and then don't switch to clean energy when the income increased but consume a set of fuels which may include solid fuels depending on their preference, need and their budget [13]. The study found that both household head education level and household size have significant positive impact on household adaptation of improved cook stove [9].

The study Designated that increase of household size prefer to use traditional fuels to modern clean fuels [14]. The study discovered that preparing traditional meals increase the likelihood of using fuels wood hence significant influence of using traditional cook stove for rural household despite the introduction of improved cook stove so this believes influence both choices for existing cook stove and adaptation of new model [13]. According to the study carried out in rural Kenya the revealed that purchasing improved cook stove for the household was influenced by the neighbor experience and relative who have already adapted the stoves [15]. The study discovered that opinions and pure pressure within the community influence household adaptation of improved cook stove in Bangladesh $[12,16]$. The authors Concluded that the old people are associated with high probability of adapting modern cooking fuels $[7,4,6]$, Expressed that the lack of demand for improved cook stoves especially among the low income population is driven by perceived values of cook stove such efficiency, health environment benefit and culture belief without addressing this concern, the improved cook stove will never be adapted that is why [8], they expressed that the creation of demand among the low income household will improve the adaptation of cook stoves and fuels technology.

Various studies have been conducted in developing countries to identify the factors that determine household cook stove decision, in Rwanda studies carried out particularly in both urban and rural area, attempted to distinguish the determine factors of fuels and cook stove adoption with measure concentration on institutional and stove relation factors and little on disaggregated level factors using panel data.

This study will contribute to existing literature though providing empirical evidence of the factors influencing the household adaptation of improved cook stove as the previous studies showed that Multinomial probability models using cross-section data are unsuitable for investigating the cook stove adaptation at household level which requires panel data.

\section{Methodology}

\section{The Theoretical Framework}

Binary logistic regression is frequently used as regression approach for evaluating discrete choice data such as household adoption improved cook stove, household adoption of improved cook stove is modeled as dictums variables with values 1 if household adopt cook stove and 0 otherwise, the probability of household adoption of improved stove is formulated as function of household level driving factors, the predictor variable in the model include attributes of individual and household characteristics that could influence the decision to adopt improved solid fuel stove,

According to the study, binary logistic regression model has two practical advantages, where the simplicity is the first one, this emprise that logistic equation is very simple. Interpretability is the second that is inversed of linear transformation for the logit model is merely interpretable as log-odds with considering the odd ratios [3].

The binary logistic model regression:

$$
\operatorname{Ln}\left(\frac{P_{i}}{1-P_{i}}\right)=\pi_{0}+\pi_{1} X 1_{i}+\pi_{2} X 2_{i}+\cdots \ldots \ldots \pi_{k} X k_{i}+\varepsilon_{i}(1)
$$

Where the subscript I means the $i^{\text {th }}$ observation in the sample.

$\mathrm{P}$ is the probability that the household adopts the improved solid fuel cook stoves; and (1-P) is the probability that the households does not adopt an improved solid fuel cook stove.

$\pi_{0}$ is the intercept term

$\pi_{0}, \pi_{1}, \pi_{2}, \ldots \ldots \ldots \pi_{k}$ are the coefficients of interest of independent control variables $X 1_{i}, X 2_{i}, \ldots \ldots \ldots . X k_{i} \varepsilon_{i}$ is the error term

\section{Results and Analysis}

Here we first represent the results from descriptive statistics analysis and thereafter we describe the results from multinomial logit regression model. 
Table 1. Descriptive statistics of dependent and all control variables by household location in EICV5 (2016/17) to be used in Binary Logit Regression Model.

\begin{tabular}{|c|c|c|c|c|c|}
\hline \multirow{2}{*}{ Variables } & \multirow{2}{*}{ Variable Description } & \multicolumn{2}{|c|}{ Urban Households } & \multicolumn{2}{|c|}{ Rural Households } \\
\hline & & mean & S.d & mean & S.d \\
\hline \multicolumn{6}{|c|}{ Dependent variable } \\
\hline \multicolumn{6}{|c|}{ Independent /other control variables } \\
\hline Inincome & Log of household income & 13.992 & 1.619 & 13.02 & 0.948 \\
\hline valuecookstov & value of household cook stove & 7.046 & 2.17 & 7.524 & 1.659 \\
\hline amntoncookfuel & amount spent on cooking fuel & 8.449 & 1.172 & 7.487 & 1.092 \\
\hline harmscookstove & Harms happened mostly from cook stove & 0.025 & 0.156 & 0.04 & 0.195 \\
\hline non-farm & Household with non-farm activities & 0.732 & 0.443 & 0.474 & 0.499 \\
\hline homeowner & Household homeownership & 0.454 & 0.498 & 0.854 & 0.353 \\
\hline Hhsize & Household size & 4.247 & 2.4 & 4.445 & 2.053 \\
\hline hrs cooking & Total hours spent on cooking in a week & 229 & 209.1 & 222.202 & 161.473 \\
\hline hrs firewood & Total hours spent on cooking fuels & 3.913 & 15.342 & 9.719 & 23.954 \\
\hline basic educ & Household head with formal basic education & 0.242 & 0.429 & 0.224 & 0.417 \\
\hline Agehhd & Age of household head & 40.592 & 14.036 & 46.114 & 15.791 \\
\hline Polygamy & Household head marital status & 0.014 & 0.119 & 0.027 & 0.161 \\
\hline wage salary & Household having wage salary & 0.188 & 0.391 & 0.592 & 0.492 \\
\hline scecookfl & Primary source of cooking fuel (modern energy) & 0.06 & 0.237 & 0.002 & 0.045 \\
\hline Typhbt & Household type of habitat & 0.287 & 0.452 & 0.668 & 0.471 \\
\hline
\end{tabular}

Source: Author's computed using EICV5 (2016-2017).

From the table1 above report the descriptive statistics for all variables used in the binary logit model showing that in EICV5 (2016/17) on average comparison, 21.7 percent of the households adopt the usage of improved cook stoves in urban region while only 14 percent of the households adopt to use the improved cooks stoves are from rural region, not surprisingly on average 73.2 percent of households are engaged in other non-farm activities in urban region while only 47.4 percent of households in rural regions have other non-farm activities. Interestingly, 45.4 percent of households in urban region live in their own houses while 85.4 percent of the households in rural regions live in their own houses. 22 percents of households with basic formal education in rural region while only 24.2 percent of households have basic formal education in urban region. Interestingly, only 28.7 of the urban households live in umudugudu and modern planned areas while 66.8 percent of the rural households live in umudugudu and the modern planned areas.

More interestingly rural households spent more time on cooking fuel at average of 10 hours while urban households only spent averaged time of 4 hours on cooking fuel. The households within urban regions spend 4 hours on cooking activities while the rural households spend 3 hours in cooking activities and 6percent of urban households adopting the modern clean fuel for cooking purposes while only 0.2 percent of the rural households adopting the modern clean cooking fuel as primary sources of cooking fuel. Surprisingly, almost 4percent of rural households suffered harms happened from the cook stoves while only 2 percent of the urban households suffered from the harm happened from the cook stoves.

Results from estimations of Binary Logit Regression Model

Table 2. Estimations of factors influencing the household's adoption of improved energy technology in Rwanda.

\begin{tabular}{llll}
\hline VARIABLES & Variable Description & coefficient & S.d \\
\hline Household characteristic factors & & 0.00111 \\
Lnincome & Log of household income & $0.652^{* * *}$ & 0.028 \\
Homeowner & Household homeownership & -0.047 & 0.085 \\
non_farm & Household with non-farm activities & -0.059 & 0.061 \\
Typhbt & Household type of habitat & -0.049 & 0.063 \\
wage_salary & Household Having wage_salary & 0.008 & 0.064 \\
Polygamy & Household head marital status & $0.00835^{* * *}$ & 0.197 \\
Agehhd & Age of household head & -0.0777 & 0.002 \\
basic_educ & Household head with formal basic education & $-0.311^{* * *}$ & 0.064 \\
Urban & Household location/urban & $0.0390^{* *}$ & 0.085 \\
Hhsize & Household size & & 0.015 \\
cook stove and fuel characteristic factors & $2.24 \mathrm{e}-08^{* * *}$ & \\
valuecookstov & value of household cook stove & $-3.57 \mathrm{e}-05^{* * * *}$ & $4.34 \mathrm{e}-09$ \\
amntoncookfuel & amount spent on cooking fuel & 0.0847 & $8.97 \mathrm{e}-06$ \\
harmscookstove & Harms happened mostly from cook stove & $-0.000424^{* *}$ & 0.166 \\
hrs_cooking & Total hours spent on cooking in a week & $0.00468^{* * *}$ & 0.000 \\
hrs_firewoood & Total hours spent on cooking fuels & $7.105^{* * *}$ & 0.001 \\
Scecookfl & Primary source of cooking fuel (modern energy) & $-1.489^{* * *}$ & 1.022 \\
Constant & & 6,524 & 0.379 \\
Observations & & & \\
Notes_Titles: Standard errors in parentheses $* * *$ p $<0.01, * *$ p $<0.05, * p<0.1$ & & \\
\hline
\end{tabular}


From the table 2 above reports that when the household income increase by one unit Rwandan franc, the odds of households using the improved cook stove increases by $e^{(0.00111)}$ which 1 household additional to the households using improved cook stoves so the income is a crucial factor to be considered when adopting the modern energy technologies since the manufactured cook stoves and other improved cook stoves need to be purchased at some cost associated with its production. The odds of the households using the improved cook stoves increased by $e^{(0.652)}$ which is almost 2 households additional to that adopt the improved cook stoves when the households live in their own homes increase by one more compared the households living in the rent homes which is significant at $\mathrm{p}<0.01$. This is related the characteristics of the cook stoves since some cook stoves need to be built and fixed with in the cooking room and some other efficient cook stoves are easily movable. This shows that the homeownership driving factors is important to consider when adopting the modern energy technology like cook stoves. Surprisingly, when the age of household head increased by one more year, the odds of the households that use the improved cook stoves is increased by $e^{(0.00835)}$ which is 1 more household adopt the modern energy technology which is significant at $p<0.01$ while this is related to the fact that the aged household heads easily adopt the technology than the younger one towards the households efficient and effective consumptions. This shows that the households with older heads are more likely to adopt the improved cook stoves.

Interestingly, when the households living in the urban region increase by one additional household the odds of the households adopting the improved cook stoves decreased by $e^{(0.311)}$ which almost 1 household adopting improved energy technology where this is significant at $\mathrm{p}<0.01$ and this is related to the fact that most of the urban households use the traditional cook stoves and many of them try to shift to modern cooking fuel and the rural household mostly depend on solid biomass fuel for cooking purposes and hence the rural households are the first and more ones to adopt the improved cook stoves for effective biomass consumption.

When the household member increased by one more additional member that is the increase in the household size by one unit, the odds of the households adopting the usage of the improved cook stoves increase by $e^{(0.039)}$ which is 1 household adopting improved cook stoves while this is significant at $\mathrm{p}<0.01$. And this is associated to the fact that when the household member increase there will be increase in consumption of solid biomass fuel through cooking activities hence these households with increased size are likely to adopt the improved cook stove for effective and reduced consumption of solid biomass for cooking purposes.

Too much interesting, when the value of cook stove is increased by one unit Rwandan franc, the odds of the households adopting the improved cook stoves increased by $e^{(2.24 \mathrm{e}-08)}$ which is 1 household adopting the modern energy technology while this is significant at $p<0.01$ and this is associated to the datum that the more efficient cook stove is the more the cost it is, so when the value of the cook stoves that the household would receive when the sell their cook stove increase this will lead to increase in adoption of the cook stove when its value is increased hence more efficient cook stove adoption. When the households cooking fuel expenditure increase by one unity Rwandan franc there will be a reduced household adoption of improved cook stove by $e^{(-3.57 \mathrm{e}-05)}$ which is almost 1 household adopting the modern energy technology and this is significant at $\mathrm{p}<0.01$ while this is related to the microeconomic fact that household budget constraint govern the household expenditure. That is when the household cooking fuel expenditure increase there will be a reduction in other goods expenditures and hence reduction in cook stove expenditure leading to the decrease in improved cook stove household adoption.

Surprisingly, when the time spent on cooking activities within a week increased by one hour for the households, there will be reduction in the odds of households adopting the improved cook stoves by $e^{(-0.000424)}$ which is 1 household adopting the modern energy technology which is significant at $\mathrm{p}<0.05$ while this is related to the datum that most of efficient and manufactured cook stoves take long time for the food to be cooked enough and ready and this hinder the households with increased time spent on cooking activities in week to adopt the modern energy technology for their time allocation in cooking activities. When the time spent by the household on cooking fuels increased by one more hour additional the odds of the households adopt using the improved cook stove incline by $e^{(0.00468)}$ which is 1 household adopt to use the modern energy technology like improved cook stove which is significant at $\mathrm{p}<0.01$ and this is linked to the fact that when the household spend much time on the cooking fuels the households try to reduce the time spent of cooking fuels by using the efficient and effective cook stove to reduce the consumption of that fuels and hence the households that adopt to use the improved cook stove increase due to the cook stove productivity for households time allocation on cooking fuels that can be used for other income generating activities and hence increased household income.

\section{Conclusion and Recommendation}

The study carried out on the driving forces influencing the household adoption support the arguments that the households adopting to use improve cook stoves is crucial for socio economic and environmental reasons. The adoption of improved cook stove is highly reliant on the household's homeownership, total income, age of household head and the number household members while household location especially urban region slow the adoption whereas the household with polygamous household head are likely to adopt improved cook stoves so the adoption is increased by increase in household total income. The basic formal 
education for the household head is not sufficient for raising the adoption since the adoption require more information and training program about cook stove.

For the cook stove and fuel characteristics, the study shows that as the value household cook stove that is the amount received by the household from the cook stove sales increase the adoption incline while the amount spend on cooking fuel that is associated with prices of the fuel slows the adoption and rise in numbers of total hours spend on cooking fuels leads to incline in adoption. As [17] identified that there is a set constraints and barriers, although varying in different socio economic culture and environment situations contributes to slowing the adoption of improved cook stove, for example household members without formal basic education, low income for the household, inadequate of knowledge of health and environmental harms resulted from inefficient usage of biomass and lack of trainings programs for awareness about improved cook stove and these are among the main driving factors.

In Rwanda, as the subject area of this research it was identified practically that the most crucial driving factors that slow the adoption are lack of motivation, wareness and training program about the cook stove and lack direct institutional support. The study recommend that voluntary, non-governmental organization and the government should intervene to work in parallel for enhancing and developing energy policy framework like deployment and dissemination of modern energy technologies like improved cook stove in regions that are highly reliant on solid biomass. There is direct prerequisite of consistent and focused cooperation of stakeholders on the demand and the supply side as consequence this will not only enhance the health, socioeconomic and environmental situation but will also play a crucial role in achieving sustainable development goals.

\section{Conflict of Interest}

The authors declared that the study was carried out with any monetary and commercial relationships that might be the major source of conflict of interest.

\section{References}

[1] Anenberg, S.; Balakrishnan, K.; Jetter, J.; Masera, O.; Mehta, S.; Moss, J.; Ramanathan, V. (2013). Cleaner cooking solutions to achieve health, climate and economic cobenefits. environmental science and technology 47, 3944-3952.

[2] Bonjour, S. Adair-Rohani, H., Wolf, J., Bruce, N. G., Mehta, S., Pruss-Ustun, A., \& Smith, K. R. (2013). Solid fuel use for household cooking: country and regional estimates for 19802010. Environmental Health Perspective (Online), 121 (7), 784.

[3] Fox, J. (2010). Logit and Probit Models. New York: SPIDA.

[4] Gebrregziabher, Z., Mekonnen, A., Kassie, M., \& Kohlin, G. (2012). Urban energy transition and technology adoption: the case of Tigrai, Northern Ethiopia. Energy Economics 34 (2), 410-418.

[5] GIZ. (2013). Clean and Efficiency cooking energy for 100 Million homes. Bonn International cooking Energy forum 2628 June 2013.

[6] Global Alliance for clean cook stoves. (2014). Igniting Chanche: a Strategy for Universal Adoption of Clean Cook stoves and Fuels. Washington DC.: GACC.

[7] Guta, D. D. (2012). Application of an almost ideal demand system (AIDS) to Ethiopian rural residential energy use: Panel data evidence. Energy policy, 50., 528-539.

[8] Levine, D., Bertramo, I., Blalock, T. G., \& Cotterman, C. (2012). What impedes efficient adoption of products? Evidence from randomized variationin sales offers for improved cookstoves in Uganda. Uganda: GACC.

[9] Lewis, J. J., and Pattanayak, S. K. (2012). Who adopts improved fuels and cookstoves?A systematic review. Environmental health prespectives, 120 (5), 637-645.

[10] Lim, S.; Vos, T.; Flaxman, A.; Danaei, G.; Shibuya, K. (2013). A comparative risk assessment of burden of deseaseand injury attributable to 67risk factors and risk factor clusters in 21 regions, 1990-2010: a systematic analyisis for the global Burden of desease study 2010. The lancet 380, 2224-2260.

[11] Malla, M. B. NBruce, E. Bates, and E. Rehfuess. (2011). Appling global cost-benefit analysis methods to indoor air pollution mitigation interventions in Nepal, Kenya and Sudan: Insights and challenges. Energy Policy 39 (12), 7518-7529.

[12] Miller, G., \& Mobarak, M. (2013). Gender Differences in Preferences, Intra-household Externalities, and the low Demand for Improved Cookstoves. Working Paper.

[13] Ouedrago, B. (2006). Household energy preferences for cooking in urbanOuagadougou, Burkina Faso. Energy policy, 34 (18), 3787-3795.

[14] Ozcan, K. M. Gulay, E., \& Ucdogruk, S. (2013). Economic and Demographic determinants of household energy use in Turkey. Energy Policy, 60, 550-557.

[15] Person, B., Loo, J. D., Owuor, M., Ogange, L., Jefferds, M. E. D., \& Cohen, A. L. (2012). It good for my Family's Health and Cooks Food in a Way that my Heart Loves: Qualitative Findings and Imlications for Scaling up an Improved Cook stove Project in Rural Kenya. International journal of environmental research and public health, 9 (5),, 1566-1580.

[16] Pine, K., Edwards, R, Masera, O., Schilmann, A., MarronMares, A, \& Riojas-Radriguez, H. (2011). Adoption and use of improved biomass stoves in Rural MEXICO. Energy for Sustainable Development 15 (2), 176-183.

[17] Pohekar, S. D., Kumar, D., Ramachandran, M. (2005). Dissemination of cooking energy alternatives in India. Renewable and Sustainable energy Reviews, 379-393.

[18] Puzzolo, E., Stanistreet, S., Pope D., Bruce N. G, Rehfuess, E. A. (2013). Factors Influencing the Large Scale Update by Households of Cleaner and More Efficient Household Energy Technologies. A systematic Review. Evidence for policy and practice information and co-ordinating Centre. London: University of London. 
[19] Rehfuess, E. A., Puzzolo, E., Stanistreet, D., Pope, D., \&Bruce, N. G. (2014). Enablers and barriers to large scale uptake of improved solid fuel stoves: a systematic review. Environmental health perspectives, 122 (2), 120-130.

[20] Rysankova, D., Putti, V. R, Hyseni, B., Kammila, S., and Kappen, J. F. (2014). Clean and Improved Cooking Cooking in Sub-Sahara Africa. A Landscape report.
[21] Ekouevi, Koffi; Tuntivate, Voravate. 2012. Household Energy Access for Cooking and Heating: Lessons Learned and the Way Forward. A World Bank Study. Washington, DC: World Bank. (C) World Bank. 